\title{
A pintura paisagística de Hipólito Caron e as transformações do olhar no Oitocentos
}

Ana Carla de Brito ${ }^{1}$

DOI 10.20396/eha.vil4.3340

Quanto de história pode encerrar uma pintura de paisagem, para além de uma possível semelhança com o lugar representado? Ou, ainda, para além da história que o próprio suporte evidenciaria... Uma história ainda mais antiga, mais difícil de apreender talvez fosse a história do olhar desse pintor. $O$ olhar que guia a mão, ou a mão que se move conforme o olhar do artista faz perguntas. Difícil perscrutá-lo. Ainda mais por tratar-se de um artista cujos registros de pensamento e concepções não são conhecidos, se é mesmo que os deixou.

Hipólito Boaventura Caron (Resende, 1862-1892) foi um artista brasileiro atuante entre 1880 e 1891, conhecido principalmente por ter participado do Crupo Crimm. Dos dez anos de atuação do artista, cerca de três anos foram passados com o mestre Johann Ceorg Crimm, e o tempo restante se dividiu entre uma temporada na França (1885-1888) estudando com Hector Hanoteau, e os anos no Brasil (1888-1892), passados em sua maior parte na cidade de Juiz de Fora, em Minas Cerais. Sua produção artística apresenta não apenas obras de grande qualidade, como também o testemunho de maneiras de olhar a paisagem em sua época.

Camadas do olhar

Caron pinta paisagens em um período em que perdurava a hierarquia de gêneros pictóricos nas academias de belas artes, ordenamento segundo o qual a paisagem era dos gêneros menos valorizados. Ainda que desde os primeiros anos da Academia de Belas Artes do Rio de Janeiro, a pintura de paisagem tenha sido vista como proveitosa dado a exuberância da natureza brasileira ${ }^{2}$, é notável a prevalência dos outros gêneros até a década de 1880, em virtude do maior estímulo que encontravam no sistema vigente.

Nesse momento alguns intelectuais atuantes em periódicos cariocas viam na paisagem a possibilidade de a arte nacional se modernizar e encontrar uma expressão autenticamente brasilei-

\footnotetext{
1 Doutoranda pelo Programa de Pós-Graduação em Artes Visuais da UFRGS, sob orientação do prof. dr. Paulo Gomes.

2 Ver DAZZI, Camila; VALLE, Arthur. 'As bellezas naturaes do nosso paiz': o lugar da paisagem na arte brasileira, do Império à República. Concinnitas (Rio de Janeiro. Impresso), v. 1, p. 120-133, 2009.
} 
ra. Em decorrência do anseio por modernidade, esses cronistas teciam duras críticas à Academia ${ }^{3}$, reprovando o procedimento de cópia de estampas como etapa de aprendizagem do desenho. Além disso, era frequente a desaprovação às produções dos estudantes, com ressalvas elogiosas apenas para os paisagistas, principalmente aqueles ensinados por Georg Grimm

O elogio frequente a Crimm e seus estudantes reportava-se principalmente ao método de ensino do artista alemão, que preconizava a pintura ao ar livre ${ }^{5}$. Para os periodistas, essa prática favoreceria uma representação fidedigna da natureza brasileira, que passava, então, a ser o único modelo dos novos pintores. Ao invés de copiar estampas, Caron e seus colegas copiariam a própria natureza.

Entretanto, quando olhamos para a produção de Caron, percebemos, a cada período de atuação do artista a correspondência de suas pinturas com modelos compositivos de seus pares. Nos primeiros anos de atuação, quando pintava com Grimm, a composição de suas pinturas se assemeIha muito à das obras do mestre, sendo recorrente também a proximidade com a pintura de seus colegas de grupo, como se nota no conjunto de marinhas pertencentes ao Museu Nacional de Belas Artes $^{6}$.

A semelhança compositiva pode ser pensada como um esquema aprendido à priori e convocado para arranjar o que era então visto no momento da pintura, como se a referência visual de outras paisagens vistas se sobrepusesse aos olhos. Os modelos, sob essa hipótese, poderiam ser virtuais, como camadas do olhar de Caron e de seus colegas no embate com a natureza, e implicadas na percepção dela.

A função mediadora do olhar que a imagem exerceria poderia ser elucidada pelo conceito de Metaxu, como recuperado pelo filósofo italiano Emanuele Coccia7 em "A vida sensível" (2010). Metaxu foi utilizado primeiramente por Platão e designa o que está "entre dois". Coccia utiliza o

\footnotetext{
3 Ana Maria Tavares Cavalcanti discute essa questão dizendo que os detratores julgavam necessário fomentar a imagem de uma academia repressora contra a qual se pudesse expressar revolta. Ver mais a respeito em CAVALCANTI, Ana M. T. A pintura de paisagem ao ar livre e o anseio por modernidade no meio artístico carioca no final do século XIX. In: Cadernos da Pós-Graduação do Instituto de Artes/ Unicamp. Ano 6, v.6, n.1, 2002, p.28-34

4 Um exemplo dessas críticas é a realizada por Angelo Agostini, que narra uma visita feita à Academia em 1882. Ver Agostini, Revista llustrada, 23 de dezembro de 1882, ano VII, n. 326, p. 2. Disponível em: http://dezenovevinte.net/artigos_imprensa/criticas_agostini.htm

5 Georg Grimm foi professor interino da cadeira "Pintura de Paisagem, Flores e Animais" da AIBA entre 1882 e 1884.

6 As obras em questão são as seguintes: Praia da Boa Viagem (Hipólito Caron, 1884. 50,2 x 75 cm. OST. Museu Nacional de Belas Artes/Ibram, Rio de Janeiro, R]), Vista da praia da Boa Viagem [A pesca] (García y Vasques, 1883, OST, 53 x 57,5 cm. Museu Nacional de Belas Artes/Ibram, Rio de Janeiro), Vista de praia no litoral em São Domingos [Canto de Praia] (Antônio Parreiras, 1886. OST. 55,4 x 99,4 cm. Museu Nacional de Belas Artes/ Ibram, Rio de Janeiro), Porto do Rio de Janeiro (Giovani Castagneto, 1884. OST, 54,7 x $94 \mathrm{~cm}$. Museu Nacional de Belas Artes, Rio de Janeiro), e Vista da Ponta de Icaraí (Georg Grimm, 1884. OST, 81.4 X152 cm. Col. Fadel. Fonte: Catálogo O Brasil do século XIX na Coleção Fadel, 2004, p. 41.). Todas as imagens podem ser vistas em minha dissertação de mestrado, página 38, disponível em: https://lume.ufrgs.br/handle/10183/180715

7 COCCIA, E. A vida sensível. Florianópolis: Cultura e Barbárie, 2010, p. 20.
} 
termo para descrever a percepção dos seres sencientes. Concebendo imagem como forma fora de seu lugar próprio, Coccia diz que é em lugar diferente do objeto que lhe deu origem e da consciência que o percebe, que essa forma se torna imagem. Ali, a forma se descola de seu referente, ocupando um lugar intermediário onde pode se tornar imagem, e tornar-se, desse modo, perceptível aos seres sencientes. Para Coccia o espelho é um dos exemplos mais evidentes de metaxu. Ali a forma está exilada do objeto que Ihe deu origem, e também além da consciência que poderá apreendê-la. No espelho a forma se faz imagem. Assim, seja qual for o objeto a ser percebido, é necessário que se torne imagem para que seja apreendido.

Pensando com Coccia, poderíamos afirmar que as imagens já vistas, ou seja, as referências visuais apreendidas que dão origem aos esquemas compositivos são o metaxu - a instância intermediária - que permite ao artista tanto perceber o território visto, quanto ordená-lo em uma composição em sua obra.

\section{olhar como relação}

A relação do olhar com a paisagem pode ser feita de diferentes modos. Em "Poética e Filosofia da Paisagem" Michel Collot concebe o olhar como o ponto central, que media a relação dos sujeitos com o ambiente: “... a noção de paisagem envolve pelo menos três componentes ligados em uma relação complexa: um local, um olhar e uma imagem".

O olhar se estabelece a partir de um ponto de vista e faz-se percepção articulando as referências de imagem com o território abarcado pelos olhos à frente do observador. O ponto de vista que permite a percepção é singular da espécie humana, por conta, dentre outros aspectos, de seu bipedismo: "Só o homem mantém, frente ao seu meio, a distância necessária a uma visão de conjunto e à abertura de um mundo comum, que ultrapassa os limites do território"9.

Quando o ser humano se tornou bípede, seus olhos passaram da apreensão imediata e próxima ao vislumbre das distâncias, instituindo o horizonte. O olhar de conjunto coloca os elementos em relação uns com os outros, o que acontece, porém, mediante o agrupamento de perspectivas parciais que se modificam e se completam. O olhar, portanto, se estabelece como relação. A relação do ambiente com o ponto de vista de um sujeito, mas também a relação da exterioridade (o am- 
biente) com o interior desse sujeito, sua subjetividade.

Afora as questões da percepção, pode-se pensar o olhar a partir da dimensão social e histórica. Em artigo a respeito das aproximações entre imagem, arte e história, Paulo Knauss ${ }^{10}$ discute as imagens como fontes para os estudos da história, sinalizando ao longo do texto quanto às diferentes disciplinas que se ocupam das imagens em relação à história. Dissertando a respeito da abordagem da cultura visual, Knauss aponta nos trabalhos de Michael Baxandall a orientação para uma história do olhar. Em Baxandall tal abordagem se expressaria na noção de "visão de época", segundo a qual o olhar é um sentido construído socialmente e historicamente demarcado:

O equipamento mental ordena a experiência visual humana de modo variável, uma vez que este equipamento é culturalmente relativo e orienta as reações diante dos objetos visuais. O espectador se vale de uma competência visual que é socialmente estabelecida, do mesmo modo que o pintor depende da resposta de seu público. ${ }^{11}$

É devido a essa historicidade constitutiva do olhar que justapomos à percepção de Caron os modos de ver a paisagem de sua época. A paisagem se faz pela relação do olhar do indivíduo com o seu meio, mediante a percepção singular de uma subjetividade, mas é também construída socialmente, ou seja, constitui-se mediante essas combinações.

\section{olhar atento e a paysage composé}

Na AIBA, onde Caron estudou, a representação da paisagem era resultado de várias etapas, que combinava a observação da natureza em esboços com uma composição cuidadosamente pensada, posteriormente, em atelier. Ainda que o estudo da natureza também fosse valorizado e incentivado, não se constituía no procedimento central, mas em tão somente uma etapa do processo de compor uma paisagem.

Era, pois, a composição que absorvia especial cuidado dos artistas paisagistas na Academia, sendo esta finalizada em atelier. Essa modalidade de pintura era conhecida por paysage composé, cuja configuração mais recorrente apresentava uma vista distanciada e mais iluminada ao fundo, que se opunha ao primeiro plano mais escuro, com pequenas figuras humanas e fragmentos de ruínas arquitetônicas. $\mathrm{O}$ arranjo cuidadoso dos elementos na composição de atelier se fazia, porém, a 
partir de etapas precedentes: "a imaginação e a memória trabalhavam a partir das emoções e dos estudos feitos ao ar livre"12. Um exemplo dessa configuração paisagística, é a pintura "Vista do Rio de Janeiro tomada do Alto da Boa Vista" (fig. 01), de Nicolas Antoine Taunay, o primeiro professor de pintura de paisagem da AIBA, e integrante da colônia de artistas franceses que contribuíram para constituir a academia brasileira.

A produção de Caron conta com alguns quadros que apresentam vistas distanciadas e composição harmônica, e podemos até mesmo traçar um paralelo entre a pintura "Amanhecer na Floresta", de Nicolas Taunay e o quadro "Cena rural", de 1884, pertencente à Coleção Fadel'13. Comparando as duas imagens, percebemos a justaposição de diagonais, sendo uma delas perfilada pelas reses. Ainda que no quadro de Taunay os animais estejam em ação, descendo um declive enquanto são seguidos por figuras montadas, as diferenças são pequenas se comparadas ao efeito das similitudes: há uma vegetação sobranceira à esquerda, cuja disposição forma uma diagonal; em ambas as obras o conjunto de seres humanos com animais se enfileiram no centro da composição; e, finalmente, em ambas as pinturas uma pequena porção de plantas preenche o lado direito do quadro, amparando os olhos quando estes procuram o ponto de fuga.

O que acaba por imprimir dissonância entre as duas imagens é mesmo o aspecto apontado pelos críticos oitocentistas: a luz e as cores, que em Nicolas Taunay evocam os idílios claudianos, e nas paisagens de Caron e seus colegas de grupo, se fazem solares e brilhantes, e se aliam a um tratamento detalhado da forma. Como as marinhas já evocadas fazem ver, e também atestam outros numerosos exemplos, nesse período o olhar de Caron para a paisagem aparece menos amplo e panorâmico e mais minucioso tanto na representação das rochas, quanto da vegetação, sendo também abordado um espaço mais exíguo, quase como um recorte.

Valéria Salgueiro localiza esse modo de composição em um momento posterior à paisagem romântica, identificando-o com o realismo de Courbet (1819-1877), bem como com a pintura dos paisagistas de Barbizon:

[O] foco em recortes mais limitados da paisagem, que permitissem uma experiência de contato e visualização mais próxima e intensa do objeto, ia assumindo mais e mais a preferência dos paisagistas de vanguarda, como trechos do interior de florestas, fechados e sem evidenciar a recessão do espaço e do horizonte, concentrando-se a atenção em formas

\footnotetext{
12 PEREIRA, Sonia Comes. Arte, ensino e academia: estudos e ensaios sobre a Academia de Belas Artes do Rio de Janeiro. Rio de Janeiro: Mauad: FAPER], 2016, p. 160.

13 As imagens podem ser conferidas na dissertação de mestrado "Camadas do olhar: a pintura de paisagem de Hipólito Caron (1862-1892)", disponível em https://lume.ufrgs.br/handle/10183/180715
} 
e cores, e como se apresentavam à vista sob certa luz. ${ }^{14}$

Assim, embora nas pinturas de Caron seja possível perceber algumas coincidências compositivas com pinturas de paisagem clássica, o aspecto mais contundente permanece sendo a acuidade na representação de alguns elementos. Um olhar próximo e focado na verossimilhança de alguns aspectos naturais parece prevalecer sobre a composição do conjunto, ainda que seja possível distinguir o uso de alguns modelos compositivos.

Tanto a paisagem naturalista do Grupo Grimm quanto a paysage composé de Nicolas Taunay, Agostinho da Mota e outros paisagistas da AIBA, constituem representações de paisagem que aludem a modos de olhá-la.

A paysage composé é herdeira da paisagem clássica de Nicolas Poussin e Claude Lorrain, tendo sido renovada pelo trabalho de ensino e teorização de Pierre-Henri Valenciennes (1750-1819), que publicou um tratado sobre o uso da perspectiva e a pintura de paisagem em 1799, na França. O olhar paisagista clássico é tributário de uma determinada visão de época, de um modo de conceber o mundo em que o texto evocado pela pintura é mais importante do que a verossimilhança com a natureza retratada, e que a harmonia do conjunto é mais valorizada do que o pormenor do detalhe.

Já a paisagem naturalista, como realizada no século XIX, é imbuída do interesse pela verossimilhança e do apreço pelas ciências naturais, como era o caso dos pré-rafaelitas na Grã-Bretanha, que "costumavam pintar formas geológicas de modo extremamente detalhado"15. Ainda que seja temerário traçar uma genealogia ligando o grupo de artistas ingleses atuantes nas décadas de 1840 e 1850 ao grupo brasileiro, é notável a similitude na forma de olhar a paisagem

\section{Olhar enternecido}

A pintura de Caron, porém, não apresenta as mesmas características ao longo de sua carreira. Um ano após o artista partir para a França, há críticas e relatos que noticiam sobre as mudanças em seu modo de pintar e seu modo de olhar a paisagem. Talvez a crítica mais direta e contundente seja a escrita por Conzaga Duque em maio de 1886, por ocasião da exposição que ocorria na Galeria Vieitas, com quadros de Garcia y Vasquez e de Caron, enviados da França para o Rio de Janeiro. O ar-

\footnotetext{
14 SALCUEIRO, Valéria. A paisagem como gênero artístico in Antônio Parreiras: notas e críticas, discursos e contos - coletânea de textos de um pintor paisagista. Niterói: EdUFF, 2000, p. 31.

15 A paisagem na arte: 1690-1998: artistas britânicos na coleção da Tate. Curadoria e textos de Humpfreys. São Paulo: Pinacoteca do Estado, 2015, p. 125.
} 
ticulista ${ }^{16}$ aponta uma mudança no olhar dos dois paisagistas, algo que eles ainda não dominavam, o que, no entender do crítico, dava-se a ver pelos defeitos que as pinturas enviadas apresentavam:

Houve, portanto, uma transição no estudo dos dois artistas. Não que ela seja proveniente da diferença de natureza; isso seria fácil de conhecer; houve uma transição na maneira de ver e na maneira de pintar, que ainda não lhes é certa.

Por enquanto os seus estudos não merecem elogios. Aqui, faziam melhores, com a única diferença da cor e do traço.

Dois anos depois, quando Caron retorna ao Brasil e realiza uma exposição individual com 27 pinturas de paisagem europeias, Gonzaga Duque escreve outra crítica. Dessa vez ele a publica na "Revista Literária Treze de Maio"17 e dedica várias páginas ao paisagista tecendo muitos elogios às pinturas. De modo curioso, são justamente os tons de Camille Corot, um dos paisagistas franceses mais estimados por Gonzaga Duque, que se observa em vários dos quadros produzidos por Caron na Europa.

Nos anos em que esteve junto à Hanoteau, Caron pinta árvores robustas perfiladas à beira dos lagos (fig. 02), utilizando-se com frequência de efeitos de espelhamento e duplicando, assim, matizes e formas das copas das árvores. A atenção concedida às árvores, a figuração do modo específico como se apresentam, é favorecida pelo estudo ao ar livre de maneira mais extensiva e conscienciosa adotada por Hanoteau e seu círculo. Essa prática remonta, na França, às transformações recentes no modo de pintar paisagens, bem como à também nova valorização desse gênero de pintura nas instituições e salões franceses.

Corot frequentava o atelier de Jean Gigoux (mestre de Hector Hanoteau) e também passou algumas temporadas em Fontainebleau, junto aos pintores de Barbizon. Tratava-se, pois, de um artista do círculo de amigos do mestre francês de Hipólito Caron. Este, semelhantemente a Corot, passou a empregar uma paleta com cores pastéis, castanhas e escuras, iluminadas por um tom perolado que conferia à paisagem uma luz sutil. A combinação da paleta de cores rebaixada, com a luz suave e a predileção por figuras humanas solitárias junto a árvores reclinadas sobre lagos resultava em uma pintura mais melancólica do que o artista brasileiro vinha fazendo junto à natureza brasileira. Suas pinturas desse período prestam testemunho sobre um ol har que se altera, menos porque a natureza europeia diferia em cor e luz da vivacidade do ambiente brasileiro, e mais devido a uma 

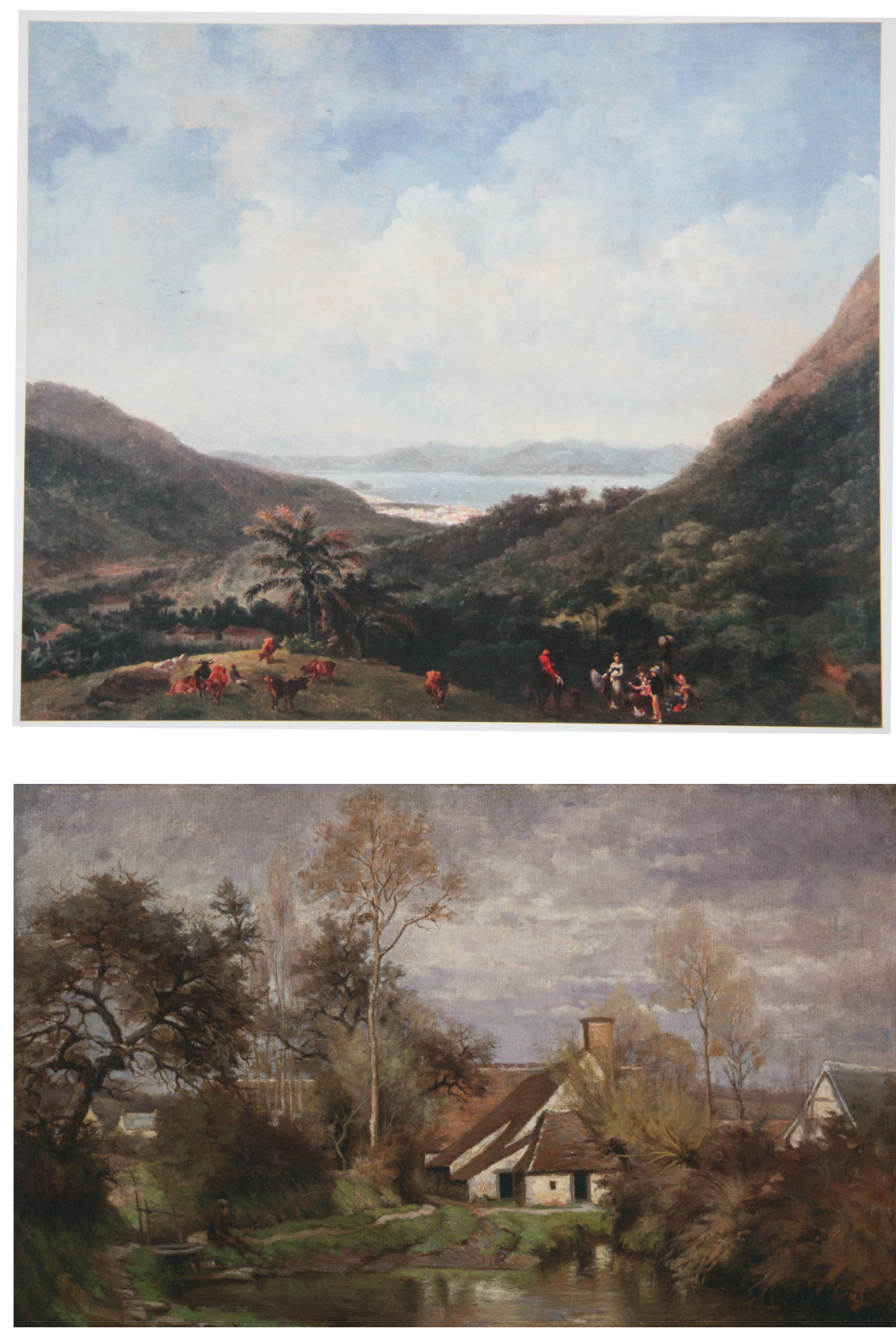

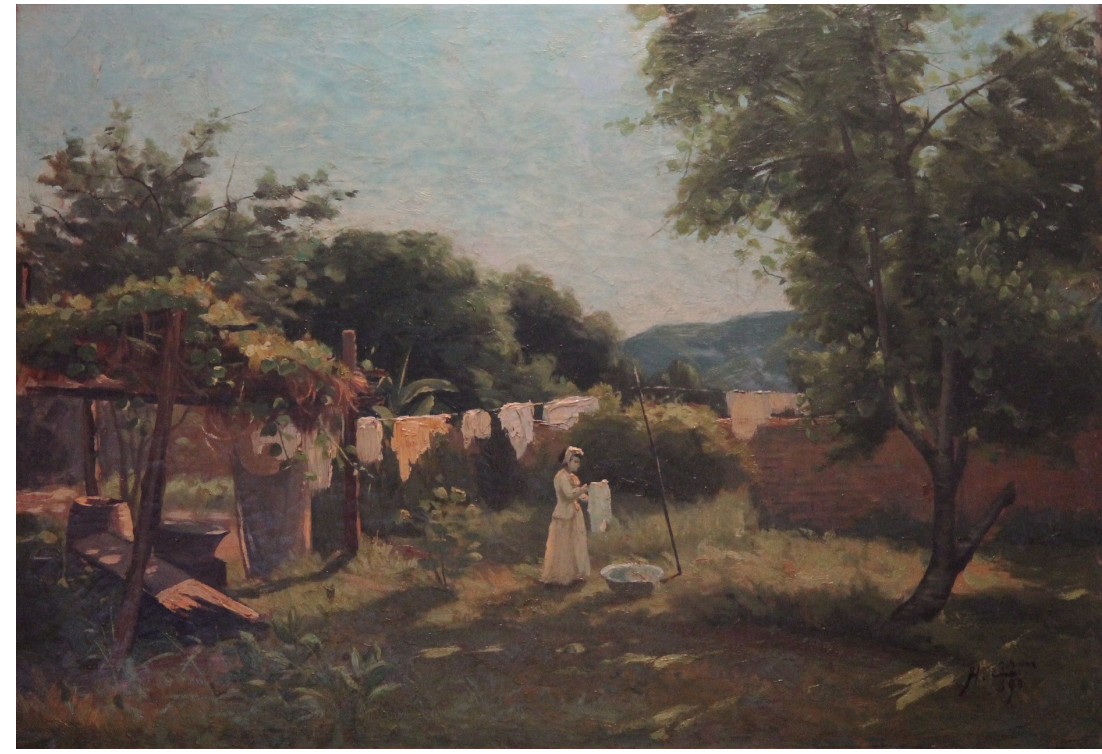

[Figura 02] Hipólito Caron. Paisagem na Bretanha, França, 1887.

Óleo sobre tela Coleção particular, Rio de Janeiro. Fonte: http://www. artedata.com/grupogrimm/HCaron15o/

[Figura 01] Nicolas Antoine Taunay. Vista do Rio de Janeiro tomada do Alto da Boa Vista. Óleo sobre tela. $52 \times 64 \mathrm{~cm}$. 1819.

Museus Castro Maya. Rio de Janeiro. Fonte: SCHWARCZ, Lilia M. O sol do Brasil: Nicolas-Antoine Taunay e as desventuras dos artistas franceses na corte de D. João. São Paulo: Companhia das Letras, 2008.

[Figura 03] Hipólito Caron. A lavadeira, 1890.

Óleo sobre tela, Col. Marcelo Sampaio. São Paulo. Foto: Ana C. Brito. 
mudança de temperamento na pintura, uma mudança na relação do artista com o que ele olha.

Interessante olhar para as pinturas europeias de Caron e perceber a recorrência de cantos calmos, da ternura pelos vegetais refletidos, junto aos quais postavam-se figuras solitárias. Ainda que o artista tivesse se estabelecido em Nevers, junto à propriedade rural de Hanoteau, e junto a seus discípulos pintasse no campo, sabe-se que circulou bastante pelo país e que tomou aulas na École Nationale Supérieure des Arts Décoratifs em Paris. Ainda assim, dentre as pinturas europeias conhecidas, não há paisagens urbanas, e as diversas novidades das grandes cidades que tanto entusiasmaram artistas, impactando seus modos de olhar, como a presença de máquinas no cotidiano, as locomotivas à vapor, a iluminação pública noturna, não são tema das pinturas do artista brasileiro.

\section{Olhar oscilante}

Ao retornar para o Brasil, Caron pinta de maneiras variadas. Após um curto tempo no Rio de Janeiro, o artista se estabelece em Juiz de Fora, onde residia sua família. Ali, além de diversas atividades em que se engajou, continuou pintando, empreendendo algumas viagens para o interior do estado de Minas Gerais. Suas pinturas entre os anos de 1889 e 1991 oscilam entre a minúcia das formas concentradas em uma faixa exígua de natureza, como na tela "Paisagem", de 1890, pertencente ao Museu Mariano Procópio, e a liberdade do emprego de manchas largas em vistas mais distanciadas e panorâmicas como em "Paisagem de Sabará”, de 1891, que integra o acervo do Museu Nacional de Belas Artes.

É também nessa época que ocorre a reforma da Academia de Belas Artes do Rio de Janeiro, que é objeto de intenso debate após a proclamação da república, e motivadora de numerosos acontecimentos ao longo do ano de $1890^{18}$. Após a reforma, jovens artistas assumem a direção da instituição, e algumas mudanças são efetuadas no programa de ensino, dentre elas há a implementação do curso de pintura em duas etapas denominadas simplesmente de "primeira" e "segunda" cadeiras de pintura, as quais não mais se distinguiam em função dos gêneros tradicionais, como ocorria na antiga Academia, mas procuravam fundir a pintura de figura e a de paisagem, demonstrando uma orientação mais moderna ${ }^{19}$.

\footnotetext{
18 Ver artigo de Miriam Seraphim (2008), "1890 - o primeiro ano da república agita o meio artístico brasileiro e marca a carreira de Eliseu Visconti", em que os acontecimentos e os debates nos jornais são descritos com minúcia.

19 Cf. DAZZI, Camila. "A Reforma de 1890": continuidades e mudanças na escola nacional de belas artes (1890-1900). Atas III Encontro de História da Arte IFCH / UNICAMP. Campinas, 2007. Disponível em: http://www.unicamp.br/chaa/eha/atas/2007/DAZZI,\%20Camila.pdf DAZZI. 2007, p. 201-202.
} 
Aparentemente Caron não tomou parte no debate da reforma, mas sabemos que ele participou das Exposiç̧̃es Gerais da Escola Nacional de Belas Artes em 1890 e 1891, sendo premiado com a segunda medalha de ouro na mostra de 1890. É possível inferir, desse modo, que ele estivesse à par das discussões a respeito do esboroamento das fronteiras entre os gêneros pictóricos. Ademais, data de 1890 uma pintura bastante singular realizada pelo artista. Trata-se de "A lavadeira" (fig. 03), em que paisagem e pintura de gênero se imiscuem de maneira difícil de se distinguir, e em que se nota um modo cuidadoso e minucioso de representação com especial atenção para os efeitos produzidos pelos raios de sol filtrados pela copa da árvore. Embora essa figura estivesse presente em outras telas do artista como "Trecho de São Domingos", de 1883, e "Paisagem com rio"20, de 1886, em nenhuma outra ocasião ela ganha a centralidade e destaque que ocorre nesta pintura. À semelhança de outros artistas, seus contemporâneos, Caron combina nessa tela a natureza variada à cena cotidiana, tornando o que seria um quadro de gênero, uma pintura que pode ser pensada como um híbrido, uma vez que é ambientada ao ar livre, e é dado bastante destaque aos elementos que comporiam a paisagem.

\section{Olhar a paisagem}

Ao longo desse texto empreendemos um breve passeio sobre as maneiras de representar paisagens próprias do tempo de Hipólito Caron, discutindo a incidência delas sobre a percepção do próprio artista. Diferente do que se poderia supor posteriormente, quando a produção paisagística oitocentista passou a ser frequentemente julgada como pintura convencional, antiquada e homogênea, se considerarmos a visão da época e os debates que a pintura de paisagem suscitou no cenário artístico brasileiro, perceberemos quão ricos e variados são os olhares engendrados pelo encontro dos artistas com a natureza.

Considerar seriamente a história do olhar em relação à paisagem é o que nos permitirá rever a história da arte e possibilitará nossa aproximação da obra. Só então poderemos realizar o que Rafael Cardoso ${ }^{21}$ considerou uma tarefa de grande complexidade: Saber ver o que viam os outros no passado, entender as pessoas, aprisionadas no contexto de sua vivência, e na clausura de seu próprio tempo.

20 As duas pinturas podem ser visualizadas no trabalho de dissertação já mencionado, nas páginas 41 e 82 . Disponível em: https://lume.ufrgs. $\mathrm{br} / \mathrm{handle} / 10183 / 180715$

21 CARDOSO, Rafael. A Arte Brasileira em 25 Quadros (1790-1930). Rio de Janeiro: Record, 2008, p. 5. 


\section{Referências bibliográficas}

A paisagem na arte: 1690-1998: artistas britânicos na coleção da Tate. Curadoria e textos de Humpfreys. São Paulo: Pinacoteca do Estado, 2015

ACOSTINI, Revista Ilustrada, 23 de dezembro de 1882, ano VII, n. 326, p. 2. Disponível em: http://dezenovevinte.net/ artigos_imprensa/criticas_agostini.htm

CAVALCANTI, Ana M. T. A pintura de paisagem ao ar livre e o anseio por modernidade no meio artístico carioca no final do século XIX. In: Cadernos da Pós-Graduação do Instituto de Artes/ Unicamp. Ano 6, v.6, n.1, 2002.

COCCIA, E. A vida sensível. Florianópolis: Cultura e Barbárie, 2010.

PEREIRA, Sonia Comes. Arte, ensino e academia: estudos e ensaios sobre a Academia de Belas Artes do Rio de Janeiro. Rio de Janeiro: Mauad: FAPER], 2016

DAZZI, Camila. "A Reforma de 1890": continuidades e mudanças na escola nacional de belas artes (1890-1900). Atas III Encontro de História da Arte IFCH / UNICAMP. Campinas, 2007. Disponível em: http://www.unicamp.br/chaa/eha/atas/2007/ DAZZI,\%20Camila.pdf

DAZZI, Camila; VALLE, Arthur. 'As bellezas naturaes do nosso paiz': o lugar da paisagem na arte brasileira, do Império à República. Concinnitas (Rio de Janeiro. Impresso), v. 1, p. 120-133, 2009.

KNAUSS, Paulo. Aproximações disciplinares: história, arte e imagem. Anos 90 (UFRGS), v. 15, p. 151-168, 2008.

SALCUEIRO, Valéria. A paisagem como gênero artístico in Antônio Parreiras: notas e críticas, discursos e contos - coletânea de textos de um pintor paisagista. Niterói: EdUFF, 2000.

SERAPHIM, Miriam N. 1890-o primeiro ano da república agita o meio artístico brasileiro e marca a carreira de Eliseu Visconti in Oitocentos - Arte Brasileira do Império à Primeira República. Org. Ana Maria T. Cavalcanti, Camila Dazzi, Arthur Valle. Rio de Janeiro: EBA-UFRJ/DezenoveVinte, 2008. 